\title{
¿Quién le teme a los derechos fundamentales? Sobre el procedimiento de tutela de la Reforma Laboral
}

Este comentario, junto a los documentos que analiza, está disponible en www.anuariocdh.uchile.cl

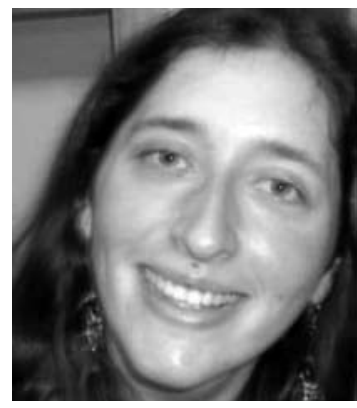

\section{Daniela Marzi Muñoz}

Licenciada en Derecho por la Universidad de Valparaíso. Magíster en Derecho del Trabajo por la Universidad de Bolonia. Profesora de Derecho del Trabajo de la Universidad de Valparaíso de Chile.

dbmarzi@yahoo.it

\section{RESUMEN}

El artículo analiza cómo la reforma laboral buscó tutelar los derechos fundamentales de las y los trabajadores. Para estos efectos revisa en forma concisa el escenario previo a la entrada en vigencia de la reforma y los cambios legislativos, para contrastarlos luego con la práctica del sistema a través del análisis crítico de tres fallos de los tribunales laborales.

Ante la pregunta sobre en qué modo la reforma procesal laboral ${ }^{1}$ se hizo cargo de la necesidad de proteger los derechos fundamentales de las/los trabajadores en la empresa, habría que responder que no sólo por medio del nuevo procedimiento de tutela pues, lamentablemente, este procedimiento no ha cumplido todas las expectativas que en él se habían depositado. No obstante, la nueva justicia ha probado tener talentos "bifrontes", pues hasta ahora ha tutelado los derechos fundamentales de las/los trabajadores por ser, en términos generales, eficaz y oportuna, lo que ha cambiado las "reglas del juego". En lo sucesivo intentaremos justificar estas aseveraciones.

La doctrina laboral nacional había destacado la necesidad de contar con un cauce jurídico idóneo para la llamada "ciudadanía en la empresa" ${ }^{2}$, título detrás del cual yace una idea simple: no por estar en una relación de trabajo, una persona deja de detentar sus derechos fundamentales frente a cualquier tipo de poder ${ }^{3}$. Esta conclusión tiene más de medio siglo y que podía advertirse

1 Establecida por las leyes $N^{\circ} 20.022$, que crea los tribunales de cobranza laboral y previsional; $N^{\circ} 20.023$, sobre normas para la cobranza judicial de cotizaciones, aportes y multas de las Instituciones de Seguridad social y $N^{\circ} 20.087$, que modifica el procedimiento de juicio del trabajo.

2 Ver UGARTE CATALDO, José Luis. La tutela de derechos fundamentales y el Derecho del trabajo: de erizo a zorro. Universidad Austral de Chile, Volumen XX-Nº 2, 2007, página 50.

3 Al respecto ver, GAMONAL, Sergio. El procedimiento de tutela de derechos fundamentales. Santiago, Legal Publishing, 2008. 
fácilmente por cualquier observador interesado en los derechos fundamentales, el ejercicio del poder en la sociedad y la democracia. En las palabras que Norberto Bobbio pronunció en la carta por medio de la que adhirió al congreso de Turín de 1957 contra las discriminaciones políticas en las fábricas, "[e]ste congreso sobre las libertades civiles en las fábricas debe brindar la ocasión de debatir uno de los problemas más graves del derecho constitucional contemporáneo: el problema de la defensa de los derechos de libertad no sólo frente a los poderes públicos, sino también frente a los poderes que siguen Ilamándose privados. Una constitución que haya resuelto el primer problema y no el segundo no puede considerarse una constitución democrática"4 ${ }^{4}$.

\section{La especial fragilidad de la tutela en el modelo chileno}

Nuestro ordenamiento, por una parte, no contaba con un procedimiento eficaz para ejercer acciones constitucionales, en circunstancias que el recurso de protección había demostrado no sólo ser inútil sino más bien paradójico ${ }^{5}$. Por otra, se trataba de un sistema carente de la estructura de defensa más potente que vio nacer y desplegarse el siglo XX para la protección de los derechos de los trabajadores a todo nivel: el derecho colectivo. Podría sostenerse que habiendo un sindicato nacional y fuera de la empresa, cuyo objeto de tutela sea efectivamente "intereses colectivos" y no las sumatorias de intereses principalmente de naturaleza salarial, los derechos fundamentales no tomarían una porción de la precariedad general de los derechos del trabajador. Es el sindicato quien analiza los puntos focales de defensa de los trabajadores e impulsa las reformas legales requeridas para hacer carne lo que en términos más generales determinan los derechos fundamentales. En Chile, la regulación del sindicato impide que éstos sean buenos representantes y defensores de los derechos laborales de los trabajadores. Al respecto la doctrina ha señalado que si el único sindicato que goza de los derechos que conforman la libertad sindical, es decir, derecho a la organización colectiva, a la negociación colectiva y a la huelga, es aquél constituido a nivel de empresa, éste no tiene posibilidad de promover y defender intereses colectivos que no sean el agregado de los objetivos remuneracionales ${ }^{6}$ del grupo que constituye cada organización colectiva. El rasgo de solidaridad propio del sindicalismo sólo puede manifestarse en agrupaciones numerosas que cubran diversas realidades laborales e incluso protejan a los trabajadores una vez terminada la relación laboral. Sólo así puede distinguirse esta defensa de intereses, cuya máxima expresión es la contratación colectiva, de lo que se ha llamado un simple contrato civil con sujeto plural en relación a nuestro contrato colectivo.

Lo anterior explica por qué no fue el sindicato, sino la academia y la Dirección del Trabajo, quienes instalaron el tema de los derechos fundamentales en el debate nacional. Que ésta sea la forma en que se presentan los acontecimientos no es baladí, porque priva a la materia de un elemento que a nivel de Derecho comparado termina siendo gravitante a la hora de defender este tipo de avances: cuando las conquistas son el fruto de una lucha social, esa historia de la que es detentador el movimiento sindical hace que no sea fácil quitar un derecho obtenido, porque se sabe cómo, cuándo y por qué se ganó.

4 BOBBIO, Norberto. Autobiografía. Primera Edición, Madrid, España, Alberto Papuzzi, 1998.

5 Así se manifestaba a mediados de esta década: la acción de protección había servido para acoger principalmente peticiones basadas en la propiedad (70,27\%), en el juzgamiento al juez natural (20,27\%) que, por lo demás, constituía la argumentación usual para enervar la actuación fiscalizadora y sancionadora de la Inspección del Trabajo y la libertad económica (14,86\%). UGARTE CATALDO, José Luis. Los derechos fundamentales del trabajador: el nuevo procedimiento de tutela laboral. Ensayos jurídicos. Universidad Alberto Hurtado, N², Facultad de Derecho, Escuela de Derecho, Santiago de Chile, Chile, 2006, p. 8.

6 Encuesta ENCLA 2006. Disponible en http://www.dt.gob.cl/1601/articles-95120_recurso_1.pdf [citado el 31 de julio de 2008]. 
En suma, sin una acción procesal eficaz y sin una organización sindical, la situación de los derechos fundamentales de los trabajadores en Chile era, al menos, escarpada.

\section{El talento bifronte de la reforma procesal}

Afirmamos que la reforma procesal laboral es una justicia de talentos bifrontes, ya que trajo remedio oportuno a las necesidades más urgentes de los trabajadores, en especial, al franquearles una asesoría jurídica radicada en las Defensorías laborales y un procedimiento monitorio en cuya alta efectividad radica gran parte del éxito de la reforma. La velocidad de resolución de casos por cobro de sumas de dinero de poca cuantía -que van al núcleo problemático más frecuente en los juicios laborales-, que eran económicamente insostenibles en el antiguo sistema, cambió el sistema de reglas en el mundo del trabajo, ya que la prolongada duración de un juicio en el tiempo dejó de ser una carta de negociación para el empleador. A la inversa, la tutela de derechos fundamentales sólo ha mostrado atisbos de lo que debió haber sido su poder para modificar las relaciones al interior de la empresa y su contribución al desarrollo de la democracia, sin que se confirmaran los temores con los que fue recibida en la discusión pública.

La verdadera aptitud reformista del procedimiento monitorio pasó inadvertida. Esto se aprecia en las previsiones del Ministerio de Justicia en base a las cuales se reformuló el proyecto de reforma del sistema procesal laboral y que motivó la postergación de su entrada desde el año 2007 hasta el 1 marzo de 2008. Las cifras que manejó el Ministerio sobre cuál sería el volumen de trabajo de los nuevos tribunales desglosado por tipo de procedimiento muestran una mirada bastante extraviada de lo que se daría en la realidad ${ }^{7}$. Pero la radicalidad del cambio de una justicia diagnosticada como productora de juicios terminados en primera instancia en un lapso de 356,8 días $^{8}$, a una que lo consiga en treinta días aproximadamente ${ }^{9}$, es la prueba más evidente del avance de los derechos.

\section{Implementación de la tutela y los destellos de sus potencialidades}

La tutela de derechos fundamentales era una de las figuras que generaba más expectativas del nuevo proyecto $^{10}$, porque, en cierta forma, venía a elevar las discusiones laborales de meras reclamaciones de sumas de dinero, a exigencias de democracia en la empresa, debido a que dotándose a los derechos fundamentales de tutela judicial, la posición del trabajador en su lugar de trabajo debía, en consecuencia, verse exponencialmente enriquecida. Más aún si consideramos que, al menos según su entramado legal, el objetivo central del procedimiento de tutela no se

7 Proyección Ministerio de Justicia para el Tribunal laboral de Valparaíso. Ingreso total 2009 en relación a la más alta carga de trabajo: 8.550 causas. Aplicación general: 3.768 (44,70\%). Tutela: 1.308 (15,29\%). Monitorio: 422 (4,9\%). Estadísticas del Tribunal laboral de Valparaíso, al 5 de septiembre de 2009. Ingreso total: 2.393 causas. Aplicación general: 815 (34,1\%). Tutela 50 (5,1\%). Monitorio: 1.155 (48,3\%). En: Informe sobre la implementación de la justicia laboral. Centro de Justicia de las Américas, por publicarse.

8 Cifra obtenida del documento "Bases fundamentales para la Reforma de la Justicia Laboral y Previsional", p. 55.

9 En el Tribunal laboral de Valparaíso, por ejemplo, que es uno de los que se declara con mayor sobrecarga de trabajo, en monitorio presentan 15 días de retraso en relación a los términos que le fija la ley y en aplicación general 18 días, ver "Informe sobre la implementación de la justicia laboral".

10 "La importancia política de este nuevo procedimiento de tutela de derechos fundamentales fue rápidamente captado por El Mercurio. Pese a su menor importancia cuantitativa en relación al resto de la reforma procesal laboral, este medio de prensa conservador alertaba en un editorial de primera página, en su tono habitual, lo que denomina 'la vulgarización del Derecho', por la 'discrecionalidad' que tienen los jueces laborales para declarar que en una relación laboral se han violado los derechos constitucionales". UGARTE CATALDO, José Luis. Tutela de derechos fundamentales del Trabajador. Legal Publishing, Santiago de Chile, 2009, p. 21. 
focalizaba en la revisión de los despidos, sino en la protección de derechos fundamentales dentro de relaciones laborales vigentes.

La norma central se encuentra en el artículo 485, inciso tercero, primera parte: "[s]e entenderá que los derechos y garantías a que se refieren los incisos anteriores resultan lesionados cuando en el ejercicio de las facultades que la ley le reconoce al empleador limita el pleno ejercicio de aquéllas sin justificación suficiente, en forma arbitraria o desproporcionada, o sin respeto a su contenido esencial". Es decir, esta norma pone el acento en análisis de conductas preliminarmente cubiertas por la legalidad y que el ordenamiento jurídico reconoce al empleador bajo una nomenclatura tan genérica como la "de organizar, dirigir y administrar la empresa".

Para reforzar esta finalidad, se creó la figura de la garantía de indemnidad, en virtud de la cual se considerará como una conducta lesiva de derechos fundamentales, amén de las descritas, "las represalias ejercidas en contra de los trabajadores, en razón o como consecuencia de la labor fiscalizadora de la Dirección del Trabajo o por el ejercicio de acciones judiciales" (artículo 485, inciso tercero, parte final).

Se brindó protección al trabajador y un incentivo para que éste buscara la tutela de sus derechos por medio de la garantía de indemnidad del artículo 485 inciso tercero. Quedó sólo como una de las posibles situaciones cubiertas por la tutela el que la lesión se produjera con ocasión del despido.

No obstante, debemos reconocer que esta lectura del objeto y fin de la tutela no se compadece con lo que en efecto se ha presentado durante el curso de la reforma, en el que ésta ha sido accionada mayormente asociada a despidos que han vulnerado derechos fundamentales, lo que ha reeditado parte del discurso que califica el derecho del trabajo como "el derecho del despido".

A continuación, analizaremos brevemente y siguiendo su orden cronológico tres fallos provenientes de los tribunales laborales de Copiapó, Valparaíso y Santiago, que ilustran estas afirmaciones.

\section{a. Sentencia del Tribunal laboral de Copiapó: RIT T-1-2008}

Esta sentencia abordó el caso de un despido donde se violaron derechos fundamentales. La empresa desvinculó a una trabajadora por incumplimiento grave de las obligaciones que imponía el contrato, fundándose en la lectura de una conversación Messenger, respaldada accidentalmente en el computador de la empresa, donde se habría descubierto que la trabajadora proporcionó información confidencial de la empleadora a una empresa que ésta fiscalizaba.

El Tribunal laboral aplicó al caso el Ilamado método de ponderación ${ }^{11}$. Desplegó su razonamiento en base a los juicios que debe plantearse el intérprete en orden a establecer si la medida denunciada como vulneratoria es idónea, necesaria y proporcional en sentido estricto. Este método -que proviene de la doctrina de Robert Alexy-fue recogido profusamente por la Dirección del Trabajo en los años $90^{12}$ y ha desembarcado con éxito en los fallos de la reforma.

11 Los juicios son: (a) de idoneidad exige que la restricción al derecho fundamental de que se trate permita alcanzar efectivamente un fin legítimo; (b) de necesidad implica que la restricción del derecho fundamental sea indispensable para lograr el fin legítimo, no existiendo una opción menos aflictiva o costosa, (c) de proporcionalidad en sentido estricto: cuanto mayor sea el grado de incumplimiento de un derecho fundamental en razón de la medida, tanto mayor debe ser la importancia del cumplimiento del derecho que se le enfrenta. Cfr. GAMONAL, Sergio, op. cit p. 45 y ss; UGARTE, José Luis, op. cit, p. 67 y ss, "El nuevo Derecho del Trabajo", LexisNexis, Santiago de Chile, Chile, 2007, p. 144 y ss.

12 Cfr. Dictámenes 684/50, de 1997, 4.842/300, de 1993; 8.273/337, de 1995; 287/14, de 1996; 2.309/165, de 1998; y 4.541/319, de 1998. 
Lo que admite discusión en esta sentencia es que, habiendo definido el juez que una conversación Messenger respaldada por accidente en el computador de la empresa equivalía a comunicación privada, se llegue a la ponderación ${ }^{13}$. La ponderación ya estaba hecha por la ley: las comunicaciones privadas son inviolables y las facultades de organizar, dirigir y administrar la empresa sin duda no amparan la ilegalidad, por lo que no hay cobertura jurídica y menos constitucional para su actuación de manera que haya que equilibrarla con el derecho fundamental del trabajador.

La pregunta relevante que surge es qué habría pasado si efectivamente se hubiera descubierto el traspaso de un secreto industrial. Para responder esta inquietud es necesario conectar las distintas ramas de nuestro ordenamiento jurídico, pues en tal caso estaríamos ante un eventual delito y lo que procede es hacer la denuncia a la fiscalía, la que tiene un procedimiento determinado por ley para investigar. Nótese, no estamos hablando de un problema de prueba ilícita, sino de un problema que lo precede: los empleadores no están habilitados para ir en contra de la legalidad. En cierta forma, dentro de las facultades que le entrega el ordenamiento jurídico al empleador, se ha razonado demasiado en base a la máxima de derecho privado de que lo que no está prohibido está permitido, pero violar comunicaciones privadas está prohibido, lo que ciertamente cierra el análisis antes de la ponderación. Probablemente, una conducta del trabajador que atendida su gravedad justifique una medida tan invasiva como la intervención de una comunicación privada, será constitutiva de delito, de modo que salimos de la sede laboral.

Si la resolución del caso dependiera, habiendo arribado hasta el juicio de ponderación en sentido estricto, de lo que hacia su final la sentencia calificó como un "contenido irrelevante" de lo leído en la conversación Messenger -y que fue lo que en definitiva hizo que el Tribunal considerara el despido como una conducta desproporcionada-, la señal que se envía a los empleadores es "revise las comunicaciones privadas de sus trabajadores, que de encontrar algo interesante podría irle bien en un juicio de ponderación".

Clarificar este punto resulta bastante crucial, ya que debe tenerse en cuenta que la jurisprudencia de la Corte Interamericana ha sido bastante rigurosa a la hora de calificar la legitimidad de las restricciones a los derechos fundamentales y no ha hecho distingos entre vulneraciones provenientes del Estado o de particulares, siendo lo primero que exige, verificar la legalidad ${ }^{14}$.

El fallo hace alusión a un Dictamen de la Dirección del Trabajo ${ }^{15}$, que estatuyó como límite a los límites, el que no se puede interceptar correos privados, permitiendo una modelación vía reglamento interno de la empresa de las facultades del empleador en el caso de los servidores de la empresa. ¿Puede un Dictamen definir los límites de una garantía constitucional? ¿Puede la ley remitir la regulación que le encomienda la Constitución a un instrumento que además es redactado unilateralmente por el empleador, aun cuando le imponga respeto a la dignidad del

13 En este sentido FERRADA, Juan Carlos. Abriendo camino en la tutela de derechos fundamentales en materia laboral: buenas intenciones, malos instrumentos. Revista de Derecho 2008, (Vol.XXI, № 2), p. 251-271, diciembre 2008.

14 "115. La fluidez informativa que existe hoy en día coloca el derecho a la vida privada de las personas en una situación de mayor riesgo debido a las nuevas herramientas tecnológicas y su utilización cada vez más frecuente. Este progreso, en especial cuando se trata de interceptaciones y grabaciones telefónicas, no significa que las personas deban quedar en una situación de vulnerabilidad frente al Estado o a los particulares. De allí que el Estado debe asumir un compromiso, aún mayor, con el fin de adecuar a los tiempos actuales las fórmulas tradicionales de protección del derecho a la vida privada. 116. No obstante, conforme se desprende del artículo 11.2 de la Convención, el derecho a la vida privada no es un derecho absoluto y, por lo tanto, puede ser restringido por los Estados siempre que las injerencias no sean abusivas o arbitrarias; por ello, deben estar previstas en la ley, perseguir un fin legítimo y ser necesarias en una sociedad democrática". Corte IDH. Caso Escher y otro vs. Brasil. Excepciones Preliminares, Fondo, Reparaciones y Costas. Sentencia de 26 de julio de 2009.

15 Dictamen 260-2002. 
trabajador? En este sentido, el que nuestra legislación remita al reglamento interno para definir el procedimiento de control tampoco es algo que deba aceptarse tan Ilanamente.

\section{b. Sentencias del Tribunal laboral de Valparaíso}

La causa T-2-2009 también abordó un caso de despido en el que se discriminó con motivo de la edad a una profesora. La indemnización no era el tema central, pues el colegio se allanó en la audiencia preparatoria al pago de la indemnización por años de servicio y otras prestaciones. No obstante, la trabajadora insistió en que ella esperaba una disculpa de parte de su ex empleadora. La sentenciadora declaró la existencia de una vulneración de los derechos de la trabajadora y condenó al colegio a realizar en su establecimiento, como actividad extraprogramática, una jornada especial de reflexión sobre la discriminación, a la que debía convocar a todos los miembros de la comunidad escolar, incluyendo padres y apoderados, profesores, personal no docente y estudiantes.

La Corte de Apelaciones anuló la sentencia por errónea aplicación de la prueba indiciaria ${ }^{16}$ al caso en cuestión, en base a un razonamiento de gravísimas consecuencias para el derecho del trabajo:

"Que el legislador en el artículo 493 efectivamente acepta la prueba indiciaria, pero ella está referida a las hipótesis del inciso primero del artículo 485, ocurriendo que, en la especie, la actora ha sostenido que ha sido discriminada en razón de la edad y tal caso se encuentra contemplado en el inciso segundo de esta última disposición, la que hace aplicable sólo el procedimiento a seguir a los actos de discriminación laboral del artículo $2^{\circ}$ del Código del Trabajo. Consecuentemente, la sentenciadora ha efectuado una aplicación errónea de la norma al conformarse con prueba indiciaria".

El que la Corte haga una interpretación en que concluya que el derecho a no ser discriminado no está tomado como derecho fundamental por un tema de remisiones legales y que, por lo tanto, no se rige por la prueba indiciaria, expone hasta qué punto los derechos fundamentales no gozan de mejor salud en los Tribunales de Alzada. Esta conclusión es grave no sólo por el incumplimiento de las obligaciones internacionales de Chile o de lo que su propia Constitución establece o, en último término, porque la discriminación sea una problemática particularmente presente y delicada en las relaciones laborales, de modo que si no estuviera amparada por el procedimiento de tutela reduciría intensamente su capacidad de acción. Es muy grave porque no se ha entendido por los Tribunales de Alzada que la discriminación es un problema que tiene que ver con el futuro de la democracia, cuyo éxito dependerá en gran medida de su capacidad de integrar la diversidad. En material laboral, la discriminación es tan medular que incluso no se considera suficiente la posible acción del sindicato a su respecto, postulándose la necesidad de que sea el legislador quien deba dar las reglas que imperen esas formas de integración y participación, habiéndose evidenciado desde hace mucho que el trabajo es una de las plataformas más importantes para que las personas puedan ejercer sus derechos fundamentales ${ }^{17}$.

Afortunadamente este criterio fue recientemente rectificado por la Corte Suprema, por medio de una sentencia recaída en unificación de jurisprudencia. Al efecto, la Corte Suprema señaló que

16 Dada la dificultad de acreditar una lesión a un derecho fundamental, el legislador atenuó la regla probatoria exigiéndole al demandante "indicios suficientes", que se corresponden a parámetros como el de la "duda razonable", de manera que pasa al empleador acreditar que los actos denunciados tienen una justificación objetiva y proporcionada, sobre el punto. Cfr. UGARTE CATALDO, José Luis, op. cit, p. 42 y ss.

17 Cfr. Sobre el punto NúÑEZ, Cayetano. Interculturalidad y Derecho del Trabajo: una aproximación a la gestión no discriminatoria de la diversidad cultural en la empresa. Valencia, Tirant Lo Blanch, 2009. 
"no hay razón legal que permita dejar de aplicar la norma del artículo 493, cuando se trata del procedimiento de tutela laboral por causa de despido discriminatorio, tanto más si se considera que las motivaciones de esta clase de despido violentan sin duda derechos fundamentales que la ley ha procurado tutelar $y$, desde que atentan contra la igualdad de oportunidades frente al empleo"18. Esta sentencia es determinante y tranquilizadora, pues permite poner en un lugar de tránsito a tan desafortunada declaración del derecho y solo como un episodio más de quienes le temen a los derechos fundamentales.

Pero vayamos a un ulterior aspecto de la sentencia de la Corte: la medida reparatoria consistente en una jornada de reflexión, ordenada por la sentencia del Tribunal laboral de Valparaíso. Sobre esta medida la Corte señaló que:

"[...] las medidas que la citada disposición ordena deben ser aplicadas a un empleador, en caso de estimarse que ha habido lesión de derechos fundamentales para con un trabajador, dicen relación con la persona afectada, esto es, como anota el recurrente, el beneficiado con la medida que se disponga tomar no puede ser otro que el trabajador lesionado y lo dispuesto por la sentenciadora escapa a dicho predicamento por lo que, la disposición ha sido erróneamente aplicada".

Las medidas reparatorias son una materia completamente nueva para el juez laboral, pues no se discuten sumas de dinero, sino actos que persiguen curar la indemnidad de un trabajador/a que ha padecido una vulneración a sus derechos fundamentales. La doctrina se ha pronunciado considerándolas amplias ${ }^{19}$ y lo cierto es que la norma habla de medias concretas de reparación, sin añadir restricciones, de forma tal que lo que un juez interprete quede dentro y fuera de ese radio, será sintomático de nuestra proporcional valoración de los derechos fundamentales de los trabajadores. Por lo demás, cabe una ulterior discusión sobre cómo "afecta a terceros" una invitación a una charla.

Pensamos que el referente de las medidas reparatorias, dada la materia, es decir, derechos fundamentales, debe buscarse más en el Derecho internacional de los derechos humanos que en las categorías indemnizatorias civiles. La medida reparatoria es la que hace a la esencia de la tutela ${ }^{20}$, ya que si hablamos de derechos fundamentales salimos de la lógica del interés particular y de la víctima. Esto es lo que explica además otra "familiaridad" que la tutela presenta con el sistema internacional de los derechos fundamentales: el que su acción tenga una extensa legitimación activa ${ }^{21}$.

La medida reparatoria tiende no sólo a la satisfacción de la víctima sino al restablecimiento del orden jurídico ${ }^{22}$ y es por eso que se proyecta hacia la sociedad en su conjunto, siendo uno de

18 Sentencia 7.093 de 14 de enero de 2009, con voto de minoría del Ministro Patricio Valdés. Es determinante esta sentencia también porque reconoce el sentido de la prueba indiciaria como un "alivio a la carga probatoria" del demandante. Sobre la prueba indiciaria como regla de juicio, que opera en el momento de construcción de la sentencia y que define la distribución del costo del hecho que ha quedado inciertamente determinado en la etapa probatoria, ver UGARTE CATALDO, José Luis. Tutela de derechos fundamentales y carga de la prueba. Revista de Derecho de la Pontificia Universidad Católica de Valparaíso 2009 (32), pp. 215 -228, segundo semestre de 2009.

19 Cfr. Ugarte, op. cit., p. 89.

20 Dentro del capítulo de medidas reparatorias, son pertinentes e ilustrativas las Ilamadas "medidas positivas", y en particular las "medidas positivas no materiales", que por supuesto han sido de las más resistidas por los adalides de la soberanía nacional. Sobre las teorías iusprivatistas de la reparación, ver NASH ROJAS, Claudio. Las reparaciones ante la Corte Interamericana de Derechos Humanos. Santiago, Universidad de Chile, Centro de derechos humanos, 2004.

21 Según el artículo 486 del Código del Trabajo, pueden incoar esta acción la/el trabajador afectado, la organización sindical que invoque un "interés legítimo" y la Inspección del Trabajo si, actuando dentro del ámbito de sus atribuciones, toma conocimiento de una vulneración.

22 Sobre el tema, ver GARCíA, Sergio. La jurisprudencia de la Corte Interamericana de Derechos Humanos en materia de reparaciones. En: La Corte Interamericana de Derechos Humanos. Un cuarto de siglo: 1979-2004. Corte Interamericana de Derechos Humanos, 2005. 
sus fines procurar que no se repita la conducta lesiva en el futuro. De ahí que no se pueda circunscribir un contenido específico, sino que el juez debe crear medidas que se ciñan a los fines de reparación y prevención. De no entenderlo así, habría bastado el sistema de indemnizaciones que rigen en la materia y que son las que en principio causaban tanta preocupación.

\section{c. Sentencia del Segundo Juzgado del Trabajo de Santiago}

Como corolario, destacamos esta sentencia reciente, la T-24-2009, en que se condenó a un supermercado por haber sometido a un procedimiento investigativo a algunos de sus trabajadores, debido a la pérdida de unas mercaderías cuando eran traspasadas de un establecimiento a otro. Comparte con el caso de Copiapó, el que no estaba regulado el aspecto en el reglamento interno, pero el juez penetra en un asunto mayor, en el considerando doce al indicar que "[s]e asienta en una convicción plena del sentenciador acerca de la existencia de un procedimiento investigativo discrecional del empleador, de inequívoco carácter coactivo [...] que se vale de destrezas y competencias propias de interrogatorios de testigos en contextos de presión psicológica proscritos por el orden democrático, tanto en las esferas públicas cuanto, por cierto, en las privada". Para el juez no es necesario siquiera ponderar, pues estas son acciones que escapan a la legalidad, que, como dijimos, es el primer elemento que se debe analizar.

\section{Conclusiones}

El procedimiento de tutela de derechos fundamentales en la reforma laboral abrió una senda que lanzó una serie de nuevos argumentos al debate. Su entrada en vigor ha sido discreta, pues, por una parte, el número dentro de ingresos de causas por este procedimiento a los nuevos tribunales no ha sido relevante, y por otra, lamentablemente la Defensoría Laboral estableció un sistema de control de este tipo de demandas en que debe obtenerse la autorización de la oficina nacional para que puedan interponerse. Este trámite crea un desincentivo importante para los defensores, pues se trata de un trabajo que requiere mayor dedicación y que tiene posibilidades ciertas de no lograr ningún resultado concreto en caso que la autoridad no vise la demanda. Es una lástima, porque son las defensorías gratuitas las más libres de suspicacias en cuanto a tomar decisiones sobre interponer una acción de tutela al margen incentivos económicos o de estrategias de negociación, que sí podrían presentarse entre los particulares ${ }^{23}$.

La implementación de tutela laboral es exigente, pues requiere dialogar con otras ramas del ordenamiento y establecer sus deslindes, por ejemplo, con materias penales. Igualmente, se encuentra pendiente la discusión sobre cuáles son las facultades que eventualmente el particular/empleador puede desplegar al momento de investigar un delito, pero convengamos que más allá de la promoción del respeto a la ley, una investigación criminal difícilmente puede abstraerse de limitar derechos fundamentales y es por ello que el ordenamiento jurídico encomienda esta tarea a un órgano público. Si bien es cierto que cualquiera puede investigar un delito, y de ahí el llamado "periodismo de investigación", no puede hacerlo empleando medios delictuosos: si encierro a un trabajador para interrogarle puedo cometer secuestro; si lo obligo al test del polígrafo puedo cometer amenazas o coacciones. En síntesis, si esas investigaciones se realizan contra la voluntad de los trabajadores, son antijurídicas; y si reúnen elementos típicos serán delito, y eso se encuentra extrarradio de cualquier facultad legal que el ordenamiento confiera a un empleador $y$, por tanto,

23 Por ejemplo, en la Oficina de Defensa Legal de Atacama las tutelas representan el 0,6\% de las demandas y en Valparaíso sólo se ha presentado una tutela. Ver informe CEJA (por publicar). 
sustrae dichas conductas de cualquier juicio de ponderación ${ }^{24}$. Además, su implementación deberá armonizarse con el derecho internacional de los derechos humanos, que establece parámetros altos de protección y exigentes requisitos para la restricción de los derechos fundamentales.

Asimismo, jurídicamente la implementación en efecto trae un problema interesante en cuanto a qué significa reparación. Pero para que cada avance no requiera décadas, debiera buscarse una respuesta en lo que se ha desarrollado el derecho internacional asumiendo que el carácter privado del derecho del trabajo es una ideología 25 .

La reforma supone, además, una revisión de las propias categorías laborales, por ejemplo, del reglamento interno de la empresas. Pareciera que éste ha sido dotado de virtudes más portentosas de las que debiera, en cuanto a su aptitud reguladora de derechos dentro de la empresa ya que, junto con no ser el instrumento jurídico idóneo para cumplir esta función, más bien se está mostrando como el legitimador de las vulneraciones cotidianas de derechos de la empresa ${ }^{26}$.

La reforma laboral a través del procedimiento de tutela le cobra al derecho del trabajo su deuda con la función que ocupa en el sistema jurídico garante de los derechos de los trabajadores/personas en la empresa, especialmente considerando el lugar que la empresa ocupa en las sociedades de mercado ${ }^{27}$. Esta idea no constituye ningún hallazgo reciente de la doctrina, sino que ha sido un lento avanzar hasta lograr el reconocimiento y necesidad de la reforma.

24 "La investigación de cómo ocurrió un delito y quién lo perpetró puede interesar a personas ajenas al ministerio fiscal. Pero informarse del asunto, haya comenzado o no la pesquisa fiscal, podrá hacerlo quienquiera que sea, sólo si emplea en ello medios lícitos". GUZMÁN, José Luis. El delito experimental. Revista procesal penal (59), Santiago de Chile, pp. 9-22, mayo 2007.

25 Por ejemplo, en el manual dedicado a la Introducción al Derecho, del año 1968, del profesor Manuel De Rivacoba, sobre el punto se sostenía que seguir considerándolo privado era ya "un resto anacrónico [...] Con su gran autoridad en estas cuestiones, Krotoschin enseña que componen este Derecho normas de la más diversa índole, por su contenido, finalidad y procedencia, y que, si bien hay en él materias claramente privadas o públicas, no es factible, ni tampoco necesario, decidirse en términos inequívocos acerca del mismo conjunto, pues no pertenece ni a una ni a otra de las dos categorías tradicionales", DE RIVACOBA, Manuel. División y Fuentes del Derecho positivo. Primera Edición, Valparaíso, Edeval, 1968.

26 Como lo denuncia el "Informe anual de derechos humanos 2009" de la Universidad Diego Portales, en su capítulo dedicado al Derecho del Trabajo, p. 419 y ss.

27 "En realidad, las constituciones de los actuales Estados democráticos nacieron de una lucha secular contra el Estado, es decir, contra quienes, habiendo conquistado el más alto poder sobre los hombres, eran los únicos en condiciones de abusar de él [...] El significado fundamental de una constitución democrática consiste en establecer que el poder sobre los hombres, sea cual sea, y lo ejerza la persona o grupo que sea, debe tener límites jurídicamente establecidos [...] Uno de los signos distintivos de la actual sociedad capitalista es la concentración de grandes poderes en manos de instituciones privadas. Nos damos cuenta de que estos poderes son tan grandes como para suspender o menoscabar o incluso hacer vanas algunas libertades fundamentales que hasta ahora parecían amenazadas sólo por los órganos del poder estatal". BOBBIO, Norberto, op. cit., p.195. 